\title{
Analisis Perbandingan Kinerja Berdasarkan Kesetaraan Gender Pada PT. Astra International, Tbk. - Daihatsu Sentra Manado (Studi Pada Karyawan Bagian Marketing)
}

\author{
Valencia Kamasi \\ Willian Agustinus Areros \\ Roy F. Runtuwene \\ Jurusan Ilmu Administrasi, Program Studi Administrasi Bisnis \\ Fakultas Ilmu Sosial Dan Politik, Universitas Sam Ratulangi \\ vkamasi8298@gmail.com
}

\begin{abstract}
This study aims to see whether there are significant differences in performance based on gender equality in female employees and male employees in the marketing division of PT. Astra International, Tbk. - Daihatsu Sentra Manado. The population of this study is all employees of the marketing division of PT. Astra International, Tbk. - Daihatsu Sentra Manado, which consists of 51 employees, consisting of 36 male employees and 15 female employees. The sampling technique used is the census technique, which is to take from all existing populations to be sampled. Where there were 15 female employees and 15 male employees were taken to balance the sample of female employees. So the total sample in this study was 30 employees. Based on the results of descriptive statistical analysis, the average value for the performance of male and female employees is equally higher than the minimum value available. Although not large, the results of this study indicate that the average value of male employee performance is higher than that of overall female employees. From the results of the independent sample t-test statistical test, a significant value gives a result stating that $\mathrm{HO}$ is accepted. The results of this study state that there is no significant difference in performance between male employees and female employees in the marketing department based on gender equality.
\end{abstract}

Keywords: Employee Performance, Gender Equality

\section{Pendahuluan}

Bagian marketing PT. Astra

International, Tbk.-Daihatsu Sentra

Manado yang merupakan salah satu

tonggak dari keberhasilan perusahaan.

Karyawan pada bagian ini diisi oleh karyawa pria dan wanita yang mana karyawan pria memiliki jumlah lebih banyak dibandingkan karyawan wanita, yaitu berjumlah 51 karyawan yang terdiri dari 36 karyawan pria dan 15 karyawan wanita. Melihat kondisi pekerjaan yang mana membutuhkan tuntutan besar salah satunya pada kekuatan fisik dikarenakan ini merupakan pekerjaan lapangan, namun tidak menjadi penghalang bagi karyawan wanita yang mana hasil penjualan karyawan wanita bisa lebih banyak daripada karyawan pria. 
Tabel 1. Persentase Rata-Rata Kinerja Penjualan per Karyawan Berdasarkan Gender

\begin{tabular}{llc}
\hline Periode & \multicolumn{2}{c}{ Karyawan } \\
\cline { 2 - 3 } 2018 & Pria & Wanita \\
\hline Oktober & $6.3 \%$ & $9.25 \%$ \\
\hline November & $5.6 \%$ & $7.6 \%$ \\
\hline Desember & $6.3 \%$ & $6.2 \%$ \\
\hline
\end{tabular}

Sumber: PT. Astra Internaitonal, Tbk.-

Daihatsu Sentra Manado (2019)

Berdasarkan latar belakang diatas maka rumusan masalahnya adalah sebagai berikut: Apakah terdapat perbedaan kinerja karyawan yang signifikan berdasarkan kesetaraan gender pada karyawan bagian marketing PT. Astra International, Tbk.-Daihatsu Sentra Manado?

\section{Kinerja}

Wirawan (2009) kinerja adalah keluaran yang dihasilkan oleh fungsi-fungsi atau indikator-indikator suatu pekerjaan atau suatu profesi dalam waktu tertentu.

Menurut Soedarmayanti dalam Shaleh (2018) kinerja adalah hasil atau keluaran dari suatu proses, kinerja memiliki hubungan yang erat dengan produktivitas karena merupakan indikator dalam menentukan bagaimana usaha untuk mencapai tingkat produktivitas yang tinggi dalam suatu organisasi.

\section{Karyawan}

Menurut Undang-Undang No.13 Tahun 2003 tentang Ketenagakerjaan, tenaga kerja adalah setiap orang yang mampu melakukan pekerjaan guna menghasilkan barang dan/atau jasa untuk memenuhi kebutuhan sendiri maupun untuk masyarakat. Sedangkan menurut KBBI (Kamus Besar Bahasa Indonesia) karyawan adalah orang yang bekerja pada suatu lembaga (kantor, perusahaan, dan sebagainya) dengan mendapat gaji (upah).

Karyawan merupakan kekayaan utama dalam suatu perusahaan, karena tanpa adanya keikutsertaan mereka, aktifitas perusahaan tidak akan terlaksana. Menurut Hasibuan (2012) karyawan adalah orang penjual jasa (pikiran atau tenaga) dan mendapat kompensasi yang besarnya telah ditetapkan terlebih dahulu.

\section{Kinerja Karyawan}

Menurut Mangkunegara (2012) Kinerja karyawan (prestasi kerja) adalah hasil kerja secara kualitas dan kuantitas yang dicapai oleh seseorang karyawan dalam melaksanakan tugasnya sesuai dengan tanggung jawab yang diberikan kepadanya.

Kinerja karyawan terkait dengan apa yang diharapkan dari hasil kerja seseorang (Pio, 2015).

Menurut Bernardin and Russel (2010), terdapat enam kriteria untuk menilai kinerja karyawan: (1) Quality; (2) Quantity; (3) Timeliness; (4) Cost effectiveness; (5) Need for supervision; dan (6) Interpersonal impact. 


\section{Kesetaraan Gender}

Sedangkan Kata "gender"e dapat diartikan sebagai perbedaan peran, fungsi, status dan tanggungjawab pada laki-laki dan perempuan sebagai hasil dari bentukan (konstruksi) sosial budaya yang tertanam lewat proses sosialisasi dari satu generasi ke generasi berikutnya (Puspitawati, 2013).

Menurut Unesco (2007) dalam Effendi (2018) Kesetaraan gender adalah suatu kondisi dimana semua manusia (baik lakilaki maupun perempuan) bebas mengembangkan kemampuan personal mereka dan membuat pilihan-pilihan tanpa dibatasi oleh stereotype, peran gender yang kaku. Hal ini bukan berarti bahwa perempuan dan laki-laki harus selalu sama, tetapi hak, tanggung jawab dan kesempatannya tidak dipengaruhi oleh apakah mereka dilahirkan sebagai laki-laki atau perempuan. Kesetaraan Gender merupakan persamaan derajat antara lakilaki dan perempuan.

Adapun indikator kesetaraan gender menurut Dwidjowijoto (2007) antara lain : (1) Akses; (2) Partisipasi; (3) Kontrol; dan (4) Manfaat.

\section{Kerangka Berpikir}

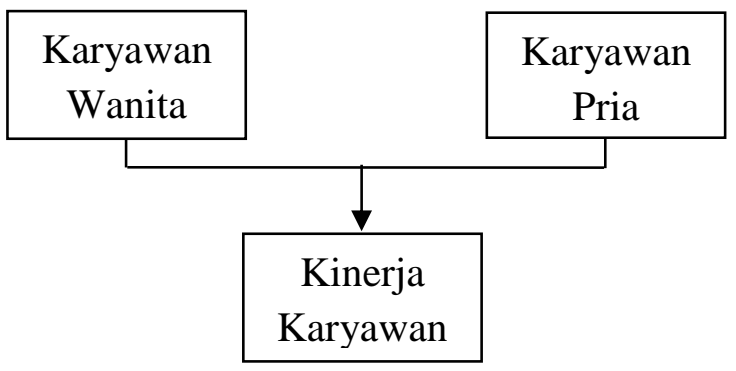

Gambar 1. Skema Kerangka Berpikir

\section{Hipotesis}

$\mathrm{H}_{0}$ : Tidak terdapat perbedaan yang signifikan antar kinerja karyawan pria dan wanita berdasarkan kesetaraan gender.

$\mathrm{H}_{\mathrm{a}}$ : Terdapat perbedaan yang signifikan antara kinerja karyawan pria dan wanita berdasarkan kesetaraan gender.

\section{Metode Penelitian}

Penelitian ini dilakukan pada 2 perusahaan cabang PT. Astra International, Tbk.-Daihatsu yang berlokasi di Manado, yaitu PT. Astra International, Tbk.Daihatsu Sales Operation Malalayang dan PT. Astra International, Tbk.-Daihatsu Sales Operation Martadinata.

Pendekatan penelitian yang digunakan adalah metode kuantitatif komparatif. Populasi dalam penelitian ini berjumlah 51 orang, sedangkan jumlah sampel yang akan diambil adalah sebanyak 30 orang yang terbagi atas 15 karyawan wanita dan 15 karyawan pria. Teknik yang dipakai untuk mengambil jumlah sampel yaitu teknik sensus, dengan mengambil seluruh jumlah populasi karyawan wanita sebagai sampel dan sebagian populasi dari karyawan pria untuk mengimbangi sampel karyawan wanita pada bagian marketing.

Teknik pengumpulan data meliputi: (1) Observasi, (2) Kuesioner. Alat-alat analisis yang digunakan dalam penelitian ini adalah: (1) Uji Validitas; (2) Uji 
Reliabilitas; (3) Uji Normalitas;

Analisis Statistik Deskriptif; dan

Independent Sample T-Test.

\section{Hasil Penelitian}

Responden dalam penelitian ini adalah karyawam bagian marketing pada PT. Astra International, Tbk. - Daihatsu Sentra Manado. Melalui hasil penyebaran kuesioner, diperoleh data keadaan responden tentang (1) Jenis Kelamin; (2) Usia; (3) Pendidikan Terakhir; dan (4) Masa Kerja.

Berikut ini hasil dari pengujian alatalat analisis yang dipakai.

Tabel 2. Hasil Pengujian Validitas Variabel Kesetaraan Gender

\begin{tabular}{cccc}
\hline Pernyataan & r Hitung & r Tabel & Keterangan \\
\hline P1 & 0,606 & 0,361 & Valid \\
\hline P2 & 0,744 & 0,361 & Valid \\
\hline P3 & 0,766 & 0,361 & Valid \\
\hline P4 & 0,584 & 0,361 & Valid \\
\hline P5 & 0,650 & 0,361 & Valid \\
\hline P6 & 0,637 & 0,361 & Valid \\
\hline P7 & 0,555 & 0,361 & Valid
\end{tabular}

Sumber : Data Primer yang diolah, 2019

Tabel 3. Hasil Pengujian Validitas Varibel Kinerja

\begin{tabular}{cccc}
\hline Pernyataan & r Hitung & r Tabel & Keterangan \\
\hline P1 & 0,675 & 0,361 & Valid \\
\hline P2 & 0,747 & 0,361 & Valid \\
\hline P3 & 0,704 & 0,361 & Valid \\
\hline P4 & 0,756 & 0,361 & Valid \\
\hline P5 & 0,828 & 0,361 & Valid \\
\hline P6 & 0,626 & 0,361 & Valid \\
\hline P7 & 0,587 & 0,361 & Valid \\
\hline P8 & 0,450 & 0,361 & Valid \\
\hline P9 & 0,646 & 0,361 & Valid \\
\hline P10 & 0,469 & 0,361 & Valid \\
\hline P11 & 0,482 & 0,361 & Valid \\
\hline P12 & 0,776 & 0,361 & Valid \\
\hline P13 & 0,703 & 0,361 & Valid \\
\hline \multicolumn{5}{l}{ Sumber : Data Primer yang diolah, 2019 }
\end{tabular}

Hasil uji validitas untuk semua nilai $r$ hitung > $\mathrm{r}$ tabel, dengan demikian semua butir pernyataan untuk variabel kesetaraan gender dan variabel kinerja dikatakan valid sehingga dapat digunakan dalam penelitian.
Tabel 4. Hasil Pengujian Reliabilitas

\begin{tabular}{ccc}
\hline Variabel & $\begin{array}{c}\text { Cronbach's } \\
\text { Alpha }\end{array}$ & Keterangan \\
\hline $\begin{array}{c}\text { Kesetaraan } \\
\text { Gender }\end{array}$ & 0,867 & Reliabel \\
\hline Kinerja & 0,880 & Reliabel \\
\hline \multicolumn{2}{l}{ Sumber : Data Primer yang diolah, 2019}
\end{tabular}

Hasil dari uji reliabilitas variabel kesetaraan gender dan variabel kinerja dinyatakan reliabel dan bisa digunakan dalam penelitian.

Tabel 5. Hasil Pengujian Normalitas

\begin{tabular}{cccc}
\hline Variabel & $\begin{array}{c}\text { Kolmogorov- } \\
\text { Smirnov }\end{array}$ & Sig. & Keterangan \\
\hline $\begin{array}{c}\text { Kinerja } \\
\text { Karyawan }\end{array}$ & 0,111 & 0,200 & $\begin{array}{c}\text { Berdistribusi } \\
\text { Nomal }\end{array}$ \\
\hline
\end{tabular}

Sumber : Data Primer yang diolah, 2019

Hasil uji normalitas variabel kinerja menggunakan Kolmogorov-Smirnov mendapatkan hasil sebesar 0,111 dengan probabilitas signifikansi 0,200 yang lebih besar dari 0,05. Sesuai dengan kriteria pengujian dapat dikatakan bahwa data tersebut berdistribusi normal.

Tabel 6. Statistik Deskriptif Variabel Kesetaraan Gender

\begin{tabular}{ccccc}
\hline $\begin{array}{c}\text { Variabel } \\
\text { Penelitian }\end{array}$ & N & Min & Mean & $\begin{array}{c}\text { Standar } \\
\text { Deviasi }\end{array}$ \\
\hline $\begin{array}{c}\text { Kesetaraan } \\
\text { Gender } \\
\text { (Pria) }\end{array}$ & 15 & 24 & 28,4 & 3,24698 \\
\hline $\begin{array}{c}\text { Kesetaraan } \\
\text { Gender }\end{array}$ & 15 & 25 & 29,1 & 2,49189 \\
(Wanita) & & & & \\
\hline \multicolumn{5}{l}{ Sumber : Data Primer yang diolah, 2019 }
\end{tabular}

Berdasarkan hasil analisis statistik deskriptif untuk variabel kesetaraan gender, nilai rata-rata baik untuk karyawan pria maupun untuk karyawan wanita sama-sama berada di atas nilai minimum. Yang artinya kedua-duanya sama-sama merasakan penerapan kesetaraan gender yang baik. Namun nilai rata-rata karyawan wanita lebih tinggi daripada karyawan pria. 
Tabel 7. Statistik Deskriptif Variabel Kinerja

\begin{tabular}{ccccc}
\hline $\begin{array}{c}\text { Variabel } \\
\text { Penelitian }\end{array}$ & N & Min & Mean & $\begin{array}{c}\text { Standar } \\
\text { Deviasi }\end{array}$ \\
\hline $\begin{array}{c}\text { Kinerja } \\
\text { (Pria) }\end{array}$ & 15 & 46 & 57,4667 & 1,46342 \\
\hline $\begin{array}{c}\text { Kinerja } \\
\text { (Wanita) }\end{array}$ & 15 & 40 & 55,2667 & 1,66037 \\
\hline \multicolumn{5}{l}{ Sumber : Data Primer yang diolah, 2019 }
\end{tabular}

Berdasarkan hasil analisis statisti deskriptif untuk variabel kinerja, nilai ratarata baik untuk karyawan pria maupun untuk karyawan wanita sama-sama berada di atas nilai minimum. Yang artinya keduaduanya sama-sama menghasilkan kinerja yang baik Namun nilai rata-rata karyawan pria lebih tinggi daripada karyawan wanita.

Tabel 8. Hasil Independent Sample t-test

\begin{tabular}{cccccc}
\hline Variabel & Karyawan & Mean & $\begin{array}{c}\text { t- } \\
\text { hitung }\end{array}$ & Sig. & Keputusan \\
\hline \multirow{2}{*}{ Kinerja } & Pria & 57,4667 & \multirow{2}{*}{0,994} & 0,3 & \multirow{2}{*}{$\mathrm{H}_{0}$ diterima } \\
\cline { 2 - 3 } & Wanita & 55,2667 & & 29 & \\
& hasil & & &
\end{tabular}

Dari hasil uji statistik independent sample t-test yang dilakukan, maka diperoleh nilai dari t-hitung sebesar 0,994 dengan derajat signifikan sebesar 0,329. Dengan melihat hasil tersebut kita bisa mengambil keputusan untuk menerima $\mathrm{H}_{0}$ karena derajat signifikansi lebih besar dari 0.05 . Kesimpulan yang bisa diambil bahwa tidak terdapat perbedaan yang signifikan antara kinerja karyawan pria dan karyawan wanita.

\section{Pembahasan}

Penjualan perusahaan selama triwulan terakhir di tahun 2018 menunjukkan kinerja penjualan karyawan wanita lebih tinggi pada bulan Oktober dan November dibanding karyawan pria. Namun terjadi perubahan pada bulan Desember 2018, dimana kinerja penjualan karyawan pria lebih tinggi dari karyawan wanita. Jumlah karyawan wanita dan pria juga cukup berbeda jauh, dimana terdapat 51 karyawan pada bagian marketing, yang terdiri dari 36 pria dan 15 wanita. Berdasarkan data tersebut, terlihat bahwa meskipun sebagai minoritas, karyawan wanita memiliki peluang menghasilkan kinerja yang bisa melampaui karyawan pria.

Dalam penelitian ini, yang menjadi penilaian untuk kinerja adalah dari segi quantity, quality, timeliness, cost effectiveness, need for supervision serta interpersonal impact. Dari segi kuantitas penjual berdasarkan data yang ada, kinerja karyawan wanita memang lebih tinggi dari karyawan pria selama 2 bulan berturutturut, namun dari hasil penelitian saat ini ternyata nilai rata-rata kinerja karyawan pria lebih tinggi dari karyawan wanita. Meskipun karyawan wanita unggul dalam kinerja berdasarkan kuantitas selama bulan Oktober dan November 2018, ternyata secara keseluruhan nilai rata-rata kinerja karyawan pria lebih unggul serta lebih tinggi dibandingkan karyawan wanita pada bulan Desember 2018. Perlu diperhatikan bahwa nilai rata-rata kinerja karyawan pria dan wanita tidak berbeda jauh dan keduaduanya sama-sama berada di atas nilai minimum, sehingga kedua-duanya sudah memiliki kinerja yang baik. 
Pencapaian yang baik dalam kinerja merupakan sesuatu yang positif yang harus dihargai oleh perusahaan. Tetapi, kita juga harus sadar bahwa perusahaan akan berada di ambang masalah besar, yang kelak akan berpengaruh pertumbuhannya, bila banyak karyawan merasa puas diri dengan pencapaian yang ada.

Berdasarkan hasil uji statistik independent sample t-test, nilai signifikan menunjukkan hasil yang menyatakan bahwa $\mathrm{H}_{0}$ diterima. Hasil penelitian yang dilakukan penulis dengan judul Analisis Perbandingan Kinerja Berdasarkan Kesetaraan Gender Pada PT. Astra International, Tbk.-Daihatsu Sentra Manado (Studi Pada Karyawan Bagian Marketing) menyatakan tidak terdapat perbedaan kinerja yang signifikan antara karyawan pria dan karyawan wanita berdasarkan kesetaraan gender.

Meskipun secara kuantitas karyawan wanita dinyatakan lebih unggul lewat data yang ada, namun secara keseluruhan karyawan pria dinyatakan lebih unggul daripada karyawan wanita berdasarkan hasil penelitian yang ada. Untuk hal kualitas, ketepatan waktu dan kerja sama dalam menjalankan pekerjaan, karyawan pria lebih unggul daripada karyawan wanita. Namun dari sisi efektifitas dan kemandirian, karyawan wanita lebih unggul dalam pekerjaan mereka.
Hasil penelitian ini sejalan dengan hasil penelitian yang dilakukan oleh Erly Erilya Lasut (Analisis Perbedaan Kinerja Pegawai Berdasarkan Gender, Usia Dan Masa Kerja (Studi Pada Dinas Pendidikan Sitaro) - 2017) yang menyatakan bahwa tidak terdapat perbedaan kinerja karyawan yang signifikan berdasarkan gender. Namun hasil penelitian ini tidak sejalan dengan hasil penelitian yang dilakukan oleh Safaranita Nur Effendi (Kinerja Pegawai Berdasarkan Kesetaraan Gender Di Kantor Kecamatan Batu Sopang Kabupaten Paser 2018), dimana hasil penelitian yang dilakukan Safaranita menyatakan bahwa terdapat perbedaan kinerja berdasarkan kesetaraan gender.

Melihat dari hasil penelitian ini, karena adanya kesetaraan kinerja antara karyawan pria dan wanita dimana kedua-duanya memiliki kinerja yang baik, maka bisa menjadi pertimbangan pada pihak perusahaan untuk membuka peluang lebih besar bagi para pencari kerja wanita yang ingin bergabung bersama divisi pemasaran PT. Astra International, Tbk. - Daihatsu Sentra Manado.

\section{Penutup}

Kesimpulan penelitian ini adalah: (1) Kinerja karyawan pria dan wanita memiliki nilai rata-rata di atas nilai minimum. Ini berarti bahwa karyawan pria dan wanita bagian marketing PT. Astra International, 
Tbk.-Daihatsu Sentra Manado merasakan penerapan kesetaraan gender yang baik serta dibantu oleh faktor-faktor lainnya sehingga dapat menghasilkan kinerja yang baik pula.

Hasil pengujian hipotesis yang diperoleh nilai signifikansi yang menyatakan bahwa $\mathrm{H}_{0}$ diterima. Maka dapat disimpulkan bahwa tidak terdapat perbedaan kinerja yang signifikan antara karyawan pria dengan karyawan wanita.

Saran penelitian ini adalah: (1) Mempertahankan serta meningkatkan penerapan kesetaraan gender yang sudah ada. (2) Membuka kesempatan lebih luas lagi bagi karyawan wanita dalam menunjukkan hasil kerja mereka agar dapat menghasilkan kinerja yang setara dengan karyawan pria. (3) Pihak perusahaan dapat menambah jumlah karyawan wanita pada divisi marketing dengan membuka peluang bagi para pencari kerja wanita karena melihat adanya kesetaraan kinerja antara karyawan pria dan wanita.

\section{Daftar Pustaka}

Kamus Besar Bahasa Indonesia. [Online]. Tersedia di https://kbbi.web.id/karyawan.

Diakses Selasa, 5 Maret 2019. Pukul 09.48

Bernardin , H. and Russel. 2010. Human Resource Management. New York: McGraw-Hill.

Dwidjowijoto, N. 2007. Manajemen Pemberdayaan: Sebuah Pengantar dan Panduan untuk Pemberdayaan
Masyarakat. Jakarta: PT Elex Media Komputindo.

Effendi, S. N. 2018. Kinerja Pegawai Berdasarkan Kesetaraan Gender Di Kantor Kecamatan Batu Sopang Kabupaten Paser. Jurnal Pemerintah Integratif 6, (1): 95-104. http://ejournal.pin.or.id

Hasibuan, M. 2012. Manajemen Sumber Daya Manusia. Jakarta: PT Bumi Aksara.

Mangkunegara, A. P. 2012. Manajemen Sumber Daya Manusia. Bandung: PT. Remaja Rosdakarya.

Pio, R. J.. 2015. Kepemimpinan Spiritual (Dimensi-Dimensi Sumber Daya Manusia). Yogyakarta: Kepel Press.

Puspitawati, H. (2013). Konsep, Teori Dan Analisis Gender. Institut Pertanian Bogor, Bogor.

Shaleh, M. 2018. Komitmen Organisasi Terhadap Kinerja Pegawai. Makassar: Aksara Timur.

UU RI No.13 Tahun 2003 tentang Ketenagakerjaan.

Wirawan. (2009). Evaluasi Kinerja Sumber Daya Manusia Teori Aplikasi dan Penelitian. Jakarta. Penerbit: Salemba Empat. 